\title{
Historical perspectives of The American Association for Thoracic Surgery: Alfred Blalock (1899-1964)
}

\author{
Claude A. Beaty, MD, Timothy J. George, MD, and John V. Conte, MD
}

\begin{abstract}
Alfred Blalock, the 30th president of The American Association for Thoracic Surgery (AATS), was born on April 5,1899 , in the small town of Culloden, Georgia. Located in Monroe County in central Georgia, Culloden is approximately 0.8 square miles in size and, according to the United States Census of 1900, had a population of 334. Blalock was the eldest of 5 children born to George Z. Blalock and Martha (Davis) Blalock. The elder Blalock was a merchant and the owner of a cotton plantation. Often referenced as a firm disciplinarian, ${ }^{1,2}$ Blalock's father placed a significant value on education. According to his sister, Alfred would "...rather [his] mother use the hairbrush on him than [his] father look at him hard." ${ }^{3}$ When Alfred was a youth, the family moved to nearby Jonesboro owing to his father's fading health. There, Alfred excelled in academics and athletics. At 14 years of age, he was granted admission to the senior class at the Georgia Military College of Milledgeville, a preparatory school for the University of Georgia. In 1915, he was admitted to the University of Georgia as a sophomore, bypassing the freshman year. Blalock continued to do well, although admittedly not excessively diligent in his studies. His grades were acceptable, but he had many outside interests. He played tennis, was a member of many organizations and societies, and was both the secretary and treasurer of his senior class. In his senior year he became enamored with the field of medicine, and with the help of an endorsement from his zoology professor, Dr John Campbell, Blalock applied and was accepted to the Johns Hopkins University School of Medicine after receiving his Bachelor of Arts degree in $1918 .^{1}$
\end{abstract}

On his arrival at Hopkins, Blalock continued to engage in many extracurricular activities, often at the expense of his academic performance. According to Dr Tinsley Harrison, Blalock's medical school roommate and close friend, he was devoted to tennis and golf, employed at the student bookstore, and very much a ladies' man, often spending

\footnotetext{
From the Division of Cardiac Surgery, The Johns Hopkins Medical Institutions, Baltimore, Md.

Disclosures: Dr Beaty is the Irene Piccinini Investigator in Cardiac Surgery and Dr George is the Hugh R Sharp Cardiac Surgery Research Fellow. Dr Beaty also received funds from National Institutes of Health grant T32CA126607. The authors have no relevant conflicts of interest to disclose.

Received for publication Sept 26, 2011; accepted for publication Oct 25, 2011.

Address for reprints: John V. Conte, MD, Professor of Surgery, Division of Cardiac Surgery, The Johns Hopkins Medical Institutions, 600 N Wolfe St, Blalock 618, Baltimore, MD 21287 (E-mail: jconte@jhmi.edu).

J Thorac Cardiovasc Surg 2012;143:260-3

$0022-5223 / \$ 36.00$

Copyright (C) 2012 by The American Association for Thoracic Surgery doi: $10.1016 /$ j.jtcvs.2011.10.071
}

significant time at nearby Goucher College, which was a women's college until $1986 .{ }^{3}$ Despite his average academic standing, Blalock excelled in his surgical courses and quickly determined that surgery, particularly experimental surgery, would be his future. In December of his senior year in 1921, Blalock wrote Dr William Halsted, expressing his wishes to join his famed residency at Johns Hopkins. ${ }^{2}$ However, Blalock's lack of academic excellence failed to impress Halsted and he was denied a surgical appointment. Blalock was able to secure an appointment as a urology intern and performed admirably despite, ironically, developing hydronephrosis and undergoing a nephrectomy while an intern. ${ }^{4}$ His performance that year earned him a general surgery assistant residency appointment the next year, but he was not reappointed to senior resident. In Blalock's words, "Competition became too keen, and I sought positions elsewhere without success." 2

In 1924, after losing his reappointment, Blalock began work as an extern in otolaryngology under the guidance of Dr Samuel Crowe. Recognizing Blalock's desire to become a surgeon and witnessing his tireless work ethic, Dr Crowe put in a call to Dr Harvey Cushing, a former Hopkins' surgeon, who was the chairman of surgery at the Peter Bent Brigham Hospital in Boston. ${ }^{2,4}$ Cushing agreed to interview Blalock and subsequently invited him to continue his training in Boston. Blalock initially accepted the offer. At this same time, however, Blalock's medical school roommate, Tinsley Harrison, became chief resident in internal medicine at Vanderbilt Hospital. Shortly after arriving in Nashville, Harrison successfully lobbied Dr Barney Brooks, the newly appointed chair of surgery, to offer Blalock the position of surgical chief resident at Vanderbilt. When Blalock arrived in Boston by train, there was a telegram from Harrison awaiting him. He graciously declined Dr Cushing's offer and accepted the position at Vanderbilt in July of 1925 after only 3 days in Boston. ${ }^{1,4}$

Blalock joined the faculty at Vanderbilt the following year, but in 1927 he contracted pulmonary tuberculosis and spent nearly 2 years in Trudeau Sanatorium on Saranac Lake in the Adirondack Mountains. Blalock returned to Vanderbilt in 1928, and despite requiring frequent therapeutic pneumothoraxes, he rarely missed a day of work and was very active in the laboratory. ${ }^{2}$ Even at this early stage in his career, he was an adept educator, frequently accepting students into his laboratory and allowing his young collaborators coauthorship for their work. ${ }^{1}$ In January of 1930, as his clinical responsibilities were increasing, Blalock hired 


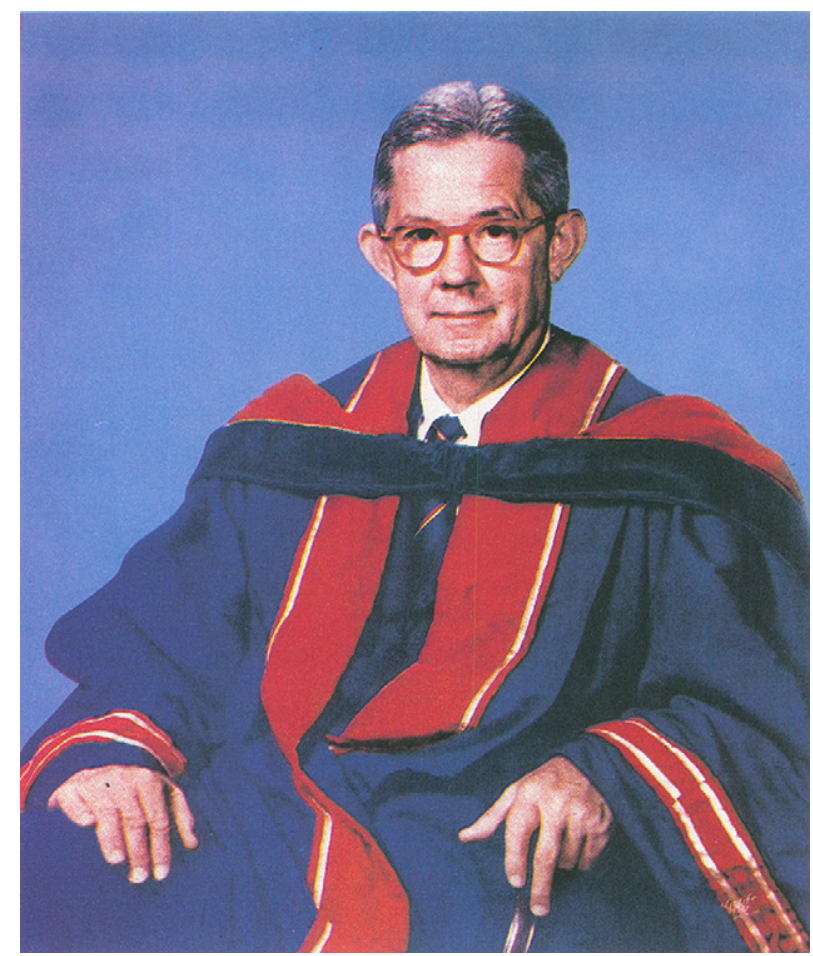

FIGURE 1. Dr Blalock in full academic regalia. (Reproduced with permission from the American College of Surgeons.)

Vivien Thomas as his full-time laboratory assistant, a relationship that grew to become one of the most fruitful of his career. Thomas was a bright man and developed into an expert experimental surgeon. Thomas and Blalock developed a lifelong collaboration in the laboratory and in the training of surgical residents. Thomas' contributions to the "blue baby operation" are legendary. 1,5

Much of Blalock's fame derived from his tenure as the chief of surgery at Johns Hopkins; however, he was not the first choice to replace Dr Dean Lewis when he stepped down in 1938. Dr Mont Reid, a former Halsted resident, was the first choice, but he declined in order to stay at the University of Cincinnati. Evarts Graham from Washington University in St. Louis, 10th president of the AATS, also declined the position but offered a strong recommendation for Blalock to Johns Hopkins' president. In 1941, at the age of 41, 19 years after graduating from medical school at Johns Hopkins, Blalock became chief of the department of surgery (Figure 1). Blalock was quick to establish himself in the operating room, and he brought his Vanderbilt research team with him to continue his basic laboratory research. He also concerned himself with the training of medical students and residents, resurrecting the tradition of Friday noon clinics (educational venues in which students would present patients to Blalock), which had initially been established by Halsted many years prior.

In 1943, Blalock was approached by Dr Edwards Park, professor of pediatrics, regarding a possible surgical

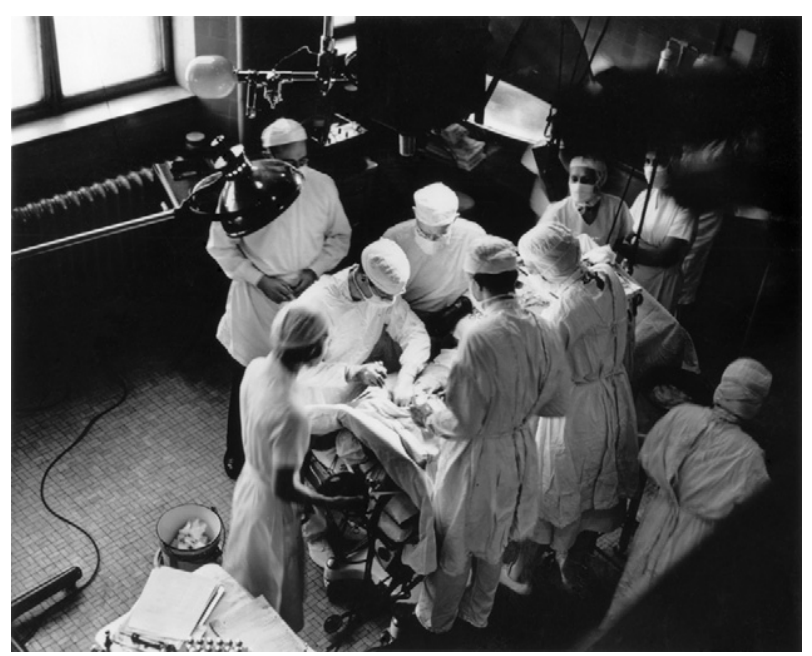

FIGURE 2. Dr Blalock and colleagues performing the "blue baby" operation on closed circuit television in 1947. He was assisted by Drs William Longmire and Denton Cooley with Mr Vivien Thomas standing behind him. (Reproduced with permission from the Johns Hopkins Medical Archives.)

alternative for children with coarctation of the aorta. Turning to his residents, Blalock asked, "I wonder how that could be approached in the laboratory?" 3 This challenge prompted a series of experiments that ultimately resulted in an anastomosis of the subclavian artery to the distal aorta. However, inasmuch as this procedure required aortic clamping, many experimental animals became paraplegic during the process. Unfortunately, the same outcome occurred during Blalock's first attempt in a human. ${ }^{1}$ At a conference discussing the outcomes of his coarctation work, Blalock met Dr Helen Taussig, head of the pediatric cardiology division. Although this encounter changed Blalock's career and pediatric cardiac surgery forever, it was his well-chronicled pragmatic application of the paradigm of surgical research that was the true hero of the day. ${ }^{2}$ On November 29 , 1944, Dr Blalock operated on a severely cyanotic infant with tetralogy of Fallot. ${ }^{1}$ According to William P. Longmire, Blalock's resident and assistant for this procedure, "It was quite amazing to see the professor gently but blindly insert a right angle clamp into the mediastinum and after dissecting over his index finger pull out the innominate artery." ${ }^{3}$ Vivien Thomas stood behind Blalock during this first operation, and many more to follow, offering a number of helpful technical suggestions throughout the procedure (Figure 2). After all, Thomas developed the procedure in the laboratory and had performed the operation hundreds of times on dogs, whereas Blalock had performed it only once, as Thomas' assistant. ${ }^{5}$ With this operation, which came to be known as the Blalock-Taussig shunt, the modern era of cardiac surgery was born. Blalock was vaulted into international fame with referrals and invitations to share his technique coming from all corners of the world. 


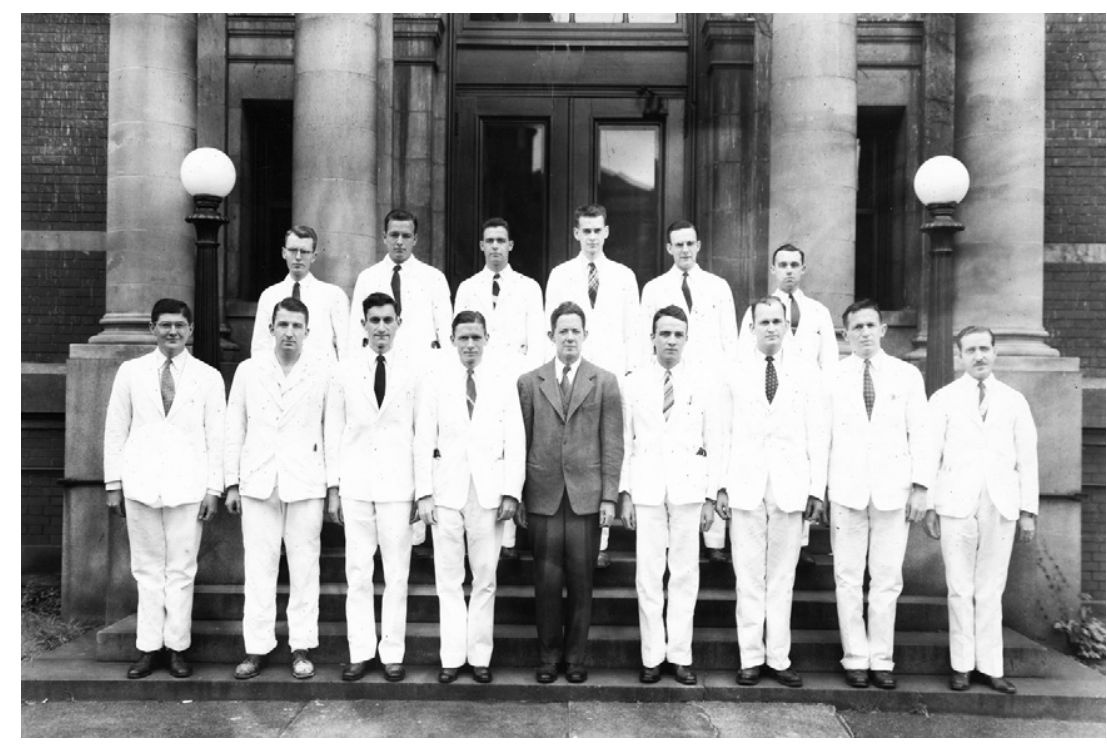

FIGURE 3. Dr Blalock with his residents in 1945. (Reproduced with permission from the Johns Hopkins Medical Archives.)

Blalock carried his reputation as a "ladies man" from medical school through his early years on the faculty at Vanderbilt, until he married his "number one girlfriend,"5 Mary Chambers O'Bryan, in Nashville, Tennessee, on October 25, 1930. Miss O'Bryan was a true southern belle known for her charm and vivacious beauty who worked in the admitting office at Vanderbilt when they met. Their wedding was reported in the society columns of the Nashville newspapers as a grand event. ${ }^{2}$ On their wedding day, Vivien Thomas, in cahoots with Blalock, parked the chief's car in front of the church during the ceremony, leaving the keys in the ignition..$^{5}$ After their declaration as husband and wife, the newlyweds initially marched calmly down the aisle, but when they reached halfway, they broke into a dead run out the church door and into their waiting car, not to be seen again for 2 weeks. Their union produced 3 children: William Rice Blalock, Mary Elizabeth Blalock, and Alfred Dandy Blalock. After Mary's death in 1958, Blalock married Alice Waters in 1959. She provided him much love and support throughout his bout with cancer, to which he succumbed on September $15,1964 .^{1,2,6}$

Blalock maintained his affection for sports and the great outdoors throughout his life. He was an avid tennis player. $\mathrm{He}$ and Tinsley Harrison were Nashville Doubles Tennis Champions in the late 1920s. He also made time for golf, fishing, and boating, hobbies that served him well on Maryland's Chesapeake Bay. Though not a natural athlete, Blalock pursued excellence in sports just as he had pursued excellence in medicine. ${ }^{6-8}$

Dr Blalock began his academic career in 1924. Two years out of medical school, he drafted his first publication in the Journal of the American Medical Association regarding the clinical course of 735 patients with biliary tract disease. ${ }^{2}$ From these origins sprang the prolific career of an exacting scientist. He pushed the boundaries of known science with probing endeavors into circulation and respiration as a young Vanderbilt faculty member. His contributions to the understanding of shock were monumental and radically changed traumatic injury resuscitation. ${ }^{5,7,9}$ Interestingly, Blalock was unable to write his original landmark paper on shock because he had tuberculosis at the time. Tinsley Harrison "ghost wrote" the paper in his stead, and it appeared in the Archives of Surgery in $1930 .{ }^{4,10}$ For his part, Dr Harrison recalls, "I had nothing to do with the conception or planning of the work on shock.... I did take his data and wrote the paper for him without a true realization on my own part of the importance of the work." ${ }^{3}$ Blalock continued to pursue academic medicine with a vengeance, amassing 40 publications from June of 1930 to June of 1934, primarily in the field of shock, but also including studies in endocrine surgery (particularly the adrenal gland), myasthenia gravis, the development of vascular suture techniques, and an attempt to create a model of pulmonary hypertension by systemic-pulmonary shunting. Blalock reached the academic rank of professor of surgery at Vanderbilt in $1938 .{ }^{11}$

Blalock's passion for education and his lasting effect on academic surgery mirrors the contributions of Halsted in its reach. During his tenure as surgeon-in-chief at Hopkins, Blalock trained 38 chief residents, of whom only 6 went into private practice. ${ }^{1,2}$ The remainder included 9 department chairmen and 10 division chiefs (Figure 3). Harrison summarized Blalock's contributions to education: "A teacher is an individual who has the capacity to influence the horizons of his pupils. Al has had that capacity all of his life...." In 1955, Blalock became chairman of the 
Medical Board of The Johns Hopkins Hospital and retired in July of 1964 with the title of professor and surgeon-inchief emeritus.

As the curtain began to fall on Blalock's life in the second half of 1964, he was visited by many of his former surgical residents and friends. These final meetings were quite endearing, best described by Dr David Sabiston, ${ }^{2}$ 65th AATS president, "These last visits made deep impressions upon us for, despite his illness and pain, he continued to maintain his gracious attitude, his appreciation, and his loyalty to all of us. As the candle grew dim, and when on September 15 the final day came, all knew that his life had been fully complete, touching a vast number of grateful patients, many admiring students, a group of loyal residents, and a host of warm friends everywhere."

\section{References}

1. Harvey AM. Alfred Blalock. In: McEuen, ed. National Academy of Sciences of the United States of America. Biographical memoirs. Vol 53. Washington, DC: National Academy of Sciences; 1982.

2. Sabiston DC. Presidential address. Alfred Blalock. Ann Surg. 1978;188:255-70

3. Ravitch MM. The Papers of Alfred Blalock. Vol 1. Baltimore, Md: The Johns Hopkins Press; 1966.

4. Chambers NK, Buchman TG. Shock at the millennium. I. Walter B. Cannon and Alfred Blalock. Shock. 2000;13:497-504.

5. Thomas VT. Pioneering research in surgical shock and cardiovascular surgery. Philadelphia, Pa: University of Pennsylvania Press; 1985.

6. Strayhorn D. Alfred Blalock. Trans Am Clin Climatol Assoc. 1965;76. xliv-vi.

7. Allen JG. Alfred Blalock and our heritage. Arch Surg. 1964;89:929-31.

8. Dalton ML. The friendship and letters of Alfred Blalock and Tinsley Harrison Am Surg. 2007;73:318-26.

9. Blalock A. Reminiscence: shock after thirty-four years. Rev Surg. 1964;21:231-4.

10. Blalock A. Experimental shock. The cause of the low blood pressure produced by muscle injury. Arch Surg. 1930;20. 959-6.

11. Alfred Blalock, MD, dies. JAMA. 1964;189:38. 